\title{
INVESTIGATING THE EFFECT OF NANOMATERIALS ON RESISTANCE PARAMETERS OF CLAY SOIL
}

\author{
JAVADZADEH P. \\ ${ }^{a}$ University of Tabriz, Tabriz, Iran.,e-mail: py.javadzadeh@gmail.com
}

Received: 20.09.2019 / Accepted: 31.10.2019/ Revised: 11.11.2019 / Available online: 10.12.2019

DOI: 10.2478/jaes-2019-0019

KEY WORDS: geotechnical, clay soil, nano, resistance parameters.

\begin{abstract}
:
In recent years, nano technology has been significantly implemented in geotechnical engineering, especially for soil remediation. Using this technology has improved soil resistance parameters and led to the stabilization of many problematic soils. Clay soils, due to their nature, have a large dispersion on the surface of the earth. The widespread dispersion of these types of soils in the site of structures, describes the necessity of studying and investigating new methods of improving and amending the resistive properties of these soils. This research is a review of the use of nanotechnology for the improvement of soil resistive properties by geotechnical researchers.
\end{abstract}

\section{INTRODUCTION}

The Regarding the locating of some important construction projects on clay soils, it is important to improve and amend them in order to create an appropriate basis for engineering projects. In recent years, nanotechnology has been widely and rapidly used in all fields, and due to the newness and lack of a complete reference in geotechnical engineering, dispersed and inadequate researches, there is a need to know how to use and the effect of nanoparticle in this field. In geotechnical engineering, clay soils in some cases have been investigated by the researchers as problematic soils in terms of loading capacity, swelling, stacking, subsidence, etc. From the past, the use of additives to amend these soils has been in order to improve the density, reduction in swelling, improve the resistance and stability desired by researchers in the field of geotechnical engineering. In recent years, as the population has grown, appropriate lands for civil projects are declining. Generally, the soil available on the site is not ideal and completely appropriate for construction from the engineering viewpoint. So, it should be prepared by making changes on it for civil activities. One of the suitable approaches in dealing with inappropriate soils in geotechnical engineering is the change in soil properties that is known to improvement or modification. There are several modification methods for improving the soil under the foundation, which can be referred to using deep foundation, poor soil removal, and replacement with filler materials, use of additives, injections, etc. Selection of the method of improvement depends on several factors such as soil type, finegrained percentage, area, and depth of improvement, the resistance, and compressibility of the intended soil, subsidence regulations, and access to technical skill, type of equipment, materials, and cost of the improvement. There are several goals for soil improvement, including increasing load capacity, increasing resistance properties, increasing slope stability, and reducing subsidence (Hashemi Tabatabaei, 2013).
Now with the advance of technology and science, nanotechnology has also opened its doors in geotechnical engineering and has interested engineers of this field to perform research in this field. The use of nanomaterials is also considered as one of the chemical methods for soil improvement, is used in most soils, and is used in this research. In this research, using geotechnical researchers" studies, a review of the use of nanomaterials has been carried out to improve the clay resistance properties.

\section{STUDY METHOD}

This research was carried out through a study of previous studies by geotechnical researchers on the effects of nanomaterials on clay resistance parameters.

\subsection{Methodological Frameworks}

We systematically identified sources for review by following the detailed process for deciding upon search terms and databases conceptualized who define a systematic review as differing from a traditional review by adopting a process that is transparent enough to be replicable by other researchers, namely by providing an audit trail of procedures and related decisions.

When filtering and analyzing the literature, we consulted the search-screen-appraise method and qualitative content analysis recommendations outlined.

\subsection{Inclusion criteria}

For a source to be considered relevant to this review, it must have provided insight into at least one of our research questions. Additionally, the study must have been available in English \& Persian from a peer-reviewed source, which is a common practice in systematic reviews. Literature was limited 
to peer-reviewed sources because these sources are highly relevant.

The final search terms were:

Clay, resistance soil, nanoparticles, nanomaterials, geotechnical engineering, soil stabilization

The final selections of databases were:
(a) EBSCO: Academic Search Complete
(b) EBSCO: Education Research Complete
(c) ProQuest
(d) Research gate
(e) Engineering Village (all databases)
(f) Google Scholar
(g) ACM Digital Library

However, the database search outlined above yielded a reasonable quantity of relevant studies.

\section{FINDINGS}

Changizi and Haddad (2018) studied the effect of using nanosilica particles to improve the mechanical and resistance properties of soft clay. Characteristics such as Atterberg limit, optimum moisture content, maximum dry weight, and compressive strength were measured in the presence of nanosilica. Nanosilica ratio was $0.5,0.7$, and $0.1 \%$ relative to the soil. The limitation has improved relative to increase in nanosilica content. Increasing ratios led to a reduction in the plasticity index and an increase in contraction limitation. The results showed that the viscose gel increased the initial stress before hardening from $70 \mathrm{Kn} / \mathrm{m} 2$ for soft clay to $300 \mathrm{Kn} / \mathrm{m} 2$ for a stabilized soil with $0.7 \%$ nanosilica. The compressive strength has increased by up to $56 \%$. Increasing the content of nanosilica resulted in a decrease in tensile stress, but an increase in the elastic modulus of the soil. Based on the results, it can be concluded that the addition of nanosilica has improved the mechanical and resistivity properties of clay. Figure 1 shows the effect of nanosilica on clay particles. Figure 2 shows the effect of nanosilica on compressive strength and figure 3 shows the effect of nanosilica on shear strength. Butron et al. (2009) studied the effect of silica nanoparticles in the range of 5-100 $\mathrm{nm}$, consolidation tests, three-axis and compressive strength on clay and showed that the soil containing nanoparticles were formable in the early stages of formation and they subsequently turn into elastoplasticity.

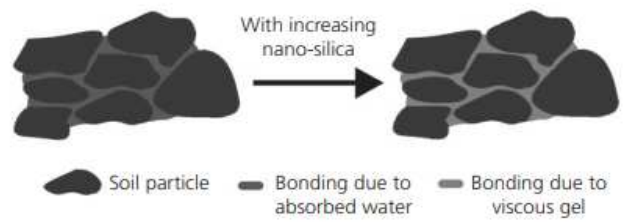

Figure 1. The effect of nanosilica on clay soil particles

Abbasi et al. (2018) investigated the effects of nanoparticles on the dispersion potential and resistance parameters of two types of clay soil with low plastic and high plastic. For this purpose, initially, identification tests were carried out on two types of clay soil and nanoparticles. Then they did pinhole experiments on soil samples with different quantities of nanoparticles including $(0,0.25,0.5,1,2$ and $4 \%$ based on dry weight).

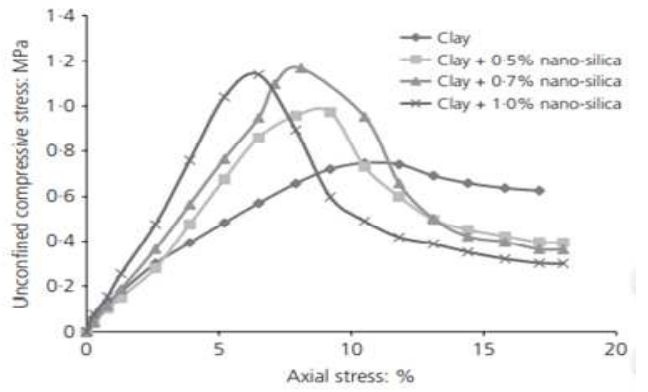

Figure 2. The effect of nanosilica on compressive strength
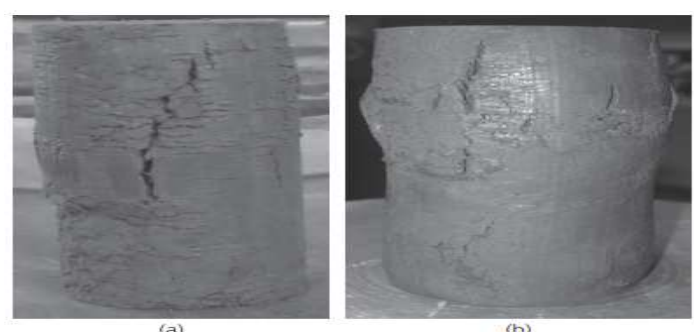

Figure 3. The effect of Nano silica on uniaxial compressive strength(UCS)

Based on the results of various experiments, it was determined that adding nanoclay to clay soils could reduce soil dispersion and improve soil resistance parameters. Table 1 depicts the effect of nanoclay on the soil adhesion potential. In this research, the soil is divided into six classes in terms of dispersion. Dispersed soils (D1 and D2), mild dispersed soils (ND3 and ND4), and non-dispersed soils (ND1 and ND2).

Table 1. The effect of nanoclay on adhesion potential of clay

\begin{tabular}{|l|l|l|l|l|}
\hline \multirow{2}{*}{ Nanoclay } & \multicolumn{4}{|c|}{ Dispersivity potential at different curing ages } \\
\cline { 2 - 5 } & Without curing & 1-day & 3-day & 7-day \\
\hline 0 & D1 & D1 & D1 & D1 \\
0.25 & D1 & D2 & D2 & D2 \\
0.5 & D1 & ND3 & ND4 & ND4 \\
1 & D1 & ND3 & ND3 & ND3 \\
2 & D1 & D2 & ND3 & ND3 \\
4 & D1 & D2 & ND3 & ND3 \\
\hline
\end{tabular}

Fakhri et al. (2012) studied the effect of nanoclay on basic geotechnical properties of kaolinite clay soil. To this end, they performed Atterberg limit and standard concentration tests for controlling the pasty behavior and optimal moisture percentage of kaolinite clay and its mixtures with different percentages of modified montmorillonite nanoclay. The results of these experiments show that the pasty range increased significantly by adding a small amount of modified montmorillonite nanoclay and the compression properties of kaolinite clay soil improves.

Majdi et al. (2017) studied the effect of adding kaolinite nanoparticles on the geotechnical properties of clay soil. In order to provide nanokaolinite, a mechanical ball mill was used, the initial powder of kaolinite was shredded in planetary ball mill machine for 10 hours, and changed into the nanometer scale (less than $100 \mathrm{~nm}$ ). The images produced by the Field Emission Scanning Electron Microscope (FESE) of nanoparticles confirm this. The obtained nanoparticles then were mixed with different soil weight ratio (CL clay soil) and the amount of soil geotechnical parameters changes before and 
after the addition of nanoparticles were investigated by compression, direct cut, and casagrande tests and optimum addition of nanoparticles was obtained. The results showed that the fluidity and pasty range of clay soil increases with increasing the number of nanoparticles to the soil composition. However, since the rate of increase in pasty range is higher than the fluidity level, the pasty index decreases which are a desirable result in geotechnical engineering to implement construction projects. In addition, according to the results of the compression experiment, the weight of volume unit of clay soil increases to a certain degree of addition of nanokaolinite, and then rapidly decreases. The adhesion of the clay soil and consequently the shear strength is also increased according to the results of the direct cutting test after addition of a certain amount of nanoparticles and does not change much after that limit. The results of XRD and XRF experiments showed that nanokaolinite causes to increase in soil adhesion and thus increases the shear strength of the soil (Majdi et al., 2017). Figure 4 shows the increase of shear strength of clay soil by addition of nanokaolinite and increase in the number of days of resistance. The direct cutting test has performed with 4, 2, and 6 $\mathrm{kg}$ weights, which are equal to 128,74 , and $222 \mathrm{kPa}$, respectively. The results showed that the shear strength of the soil under these loads increases by adding nanokaolinite to the soil composition as well as increasing the number of moisture days due to increased adhesion between soil grains.

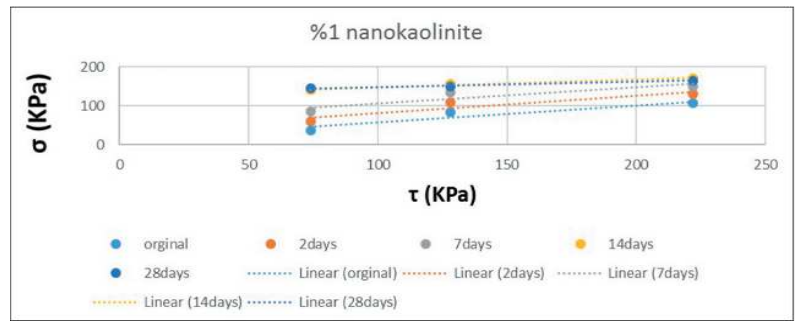

Figure 4. Increase of shear strength of clay soil by adding nanokaolinite and increase the number of moisture days

Ghafarpour Jahromi and Zahedi (2016) used nanomaterials to improve the behavioral properties of problematic clay soils in order to increase load capacity, reduce subsidence, reduce swelling, and reduce economic costs for soil stabilization in the short and long term. In this research, at first, the effect of cement on soil improvement was evaluated and then the simultaneous effect of cement and nano-aluminum on soil specifications was investigated. This investigation of these effects was done in 1-day to 28-day treatment periods. The characteristics evaluated in this study include Atterberg limit, compaction characteristics, single-axial compressive strength, California bearing ratio, and degree of acidity $(\mathrm{pH})$ for unmodified soil, modified soil with different cement contents and cement modified soil in different nanoaluminum percentages. The scanning electron microscope was also used to control and evaluate the effect of materials on the nanoscale. The results of this research show that the effect of nanoaluminum on short-term behavior is very tangible to increase the resistance and rate of corrosion so that by adding 2 nanomaterials, the single-axial resistance of the samples increased up to $20 \%$ on the first day in comparison with the corresponding samples. Also, the results of this study showed that by adding less than $6 \%$ of nanomaterial (in terms of cement weight), soil mechanical strength can be increased by more than $35 \%$ and consequently a significant part of cement consumption in soil improvement and upgrading which reflects the economic impact of nanomaterial and consequently the reduction of energy consumption and environmental pollution. Figure 5 shows a comparison of the effects of gamma nanoaluminum and processing time on single-axial compressive strength.

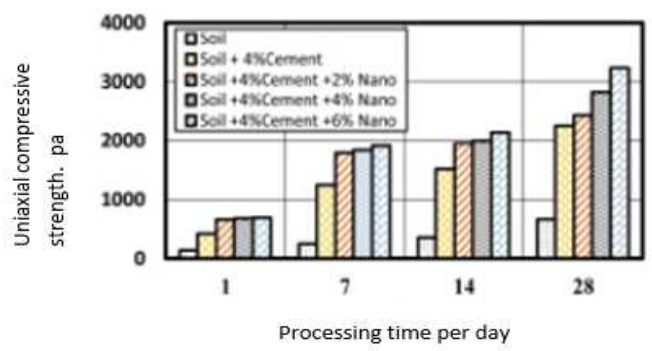

Figure 5. Comparison of the effects of gamma nanoaluminum and processing time on single-axial compressive strength

Changizi and Haddad (2015) studied the behavior of clay by adding a composition of nano iron oxide and polyester fiber. The results showed that by adding various percentages of nano iron oxide and polyester, the strength of soil parameters increased, and this increase in different percentage was until a tangible percentage and since then the increase in percentage has not had a significant effect on resistance and has no economic impact. According to the research done, the optimal percentage with the highest resistance is $1 \%$ of nano iron oxide and $0.5 \%$ polyester fiber.
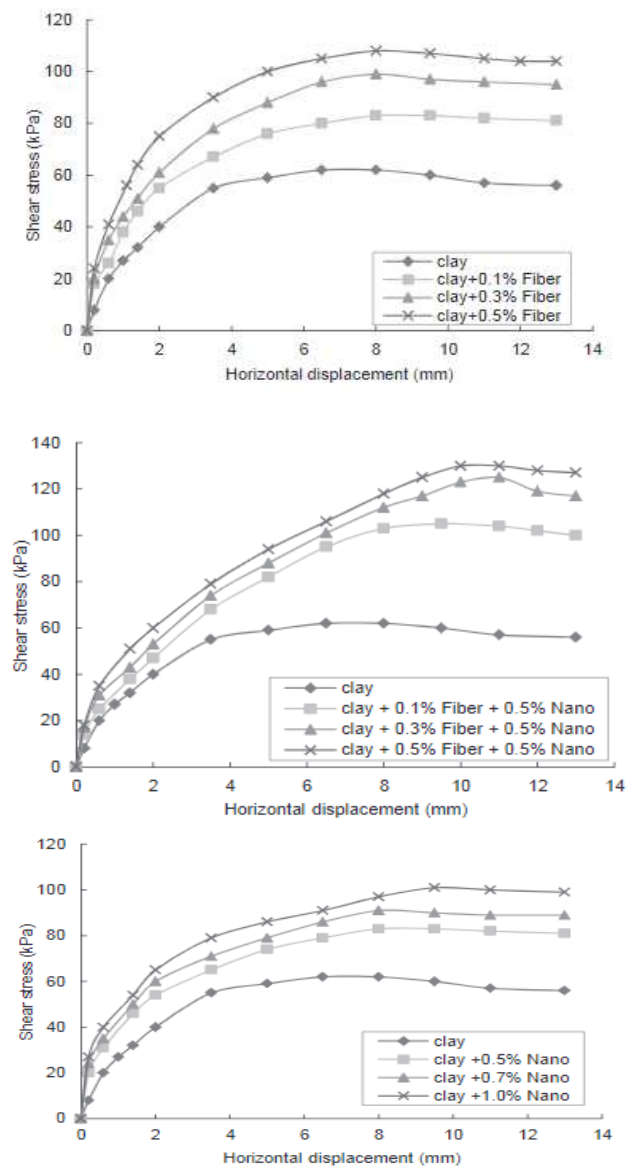

Figure 6 . The impacts of nano iron oxide and polyester fiber on soil resistance 
Tadayonfar et al. (2014) investigated the effect of polyvinyl acetate on improvement of mechanical properties of clay soils and showed that the presence of polymer leads to decrease in dry density and optimum moisture percentage relative to freeof-additive state and adding polymer leads in significantly increase in soil compressive strength after 2 hours. The researches of Majeed et al. (2014) showed that the addition of nanomaterials to clay resulted in a decrease in the compressive strength of clay. The results show that the maximum shear strength of the soil is obtained with nanoclay.

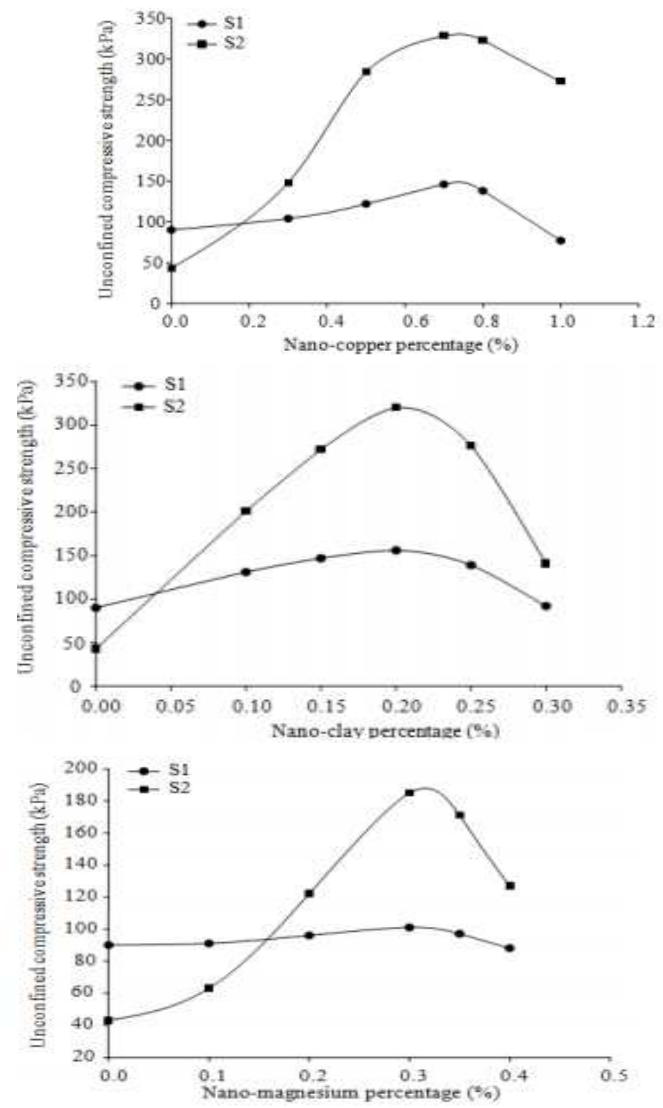

Figure 7. The effects of different nanomaterials on soil (UCS TEST)

Tabatabaei and Salamat (2013) in a research project by adding lime and polyvinyl acetate nano polymer on clay soils studied the changes in soil resistance parameters. The results of the experiments were that adding polymer to the soil changed the soil's behavior towards less water absorption and increasing the amplitude of the pasty. Adding lime to the soil, in the longterm, has a greater effect on the increase of compressive strength than the polymer, and the result obtained from the direct cutting test shows that by adding both materials, soil adhesion also increases. Neethu and Remya (2013) by performing experiments on mixture of clay with nanoclay showed that increase of nanoclay increases single-axial compressive strength and decreases the consolidation coefficient of soil. Mahmoodi and Niazian (2013), in order to evaluate the impact of nanoclay on the geotechnical properties of clay, performed compaction, direct cutting, unconfined compression and Atterberg limits tests on clay and mixed with different nanoclay percentages, and found that shear strength, compressive strength, and soil increased by increasing the nanoclay percentage to 1.5 , and decreased in higher percentages. Figure 8 shows the effect of nanoclay on compressive strength.

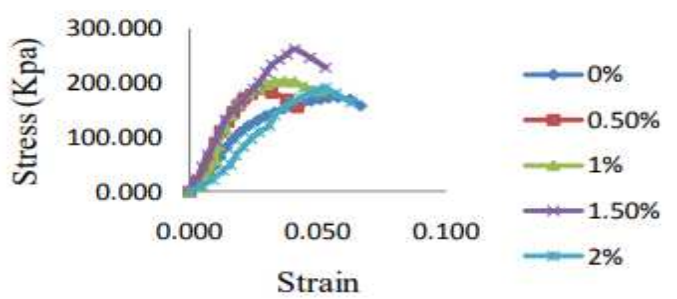

Figure 8 . The effect of nanoclay on compressive strength

Bahari et al. (2012) studied the effect of nanoclay on finegrained clay soils. The results of this research indicated the level of fluidity limit, the pasty limit, and the soil pasty index due to the adding nanoclay. They also announced that the effect of nanoclay is negative on the compression test. Because it increases the optimum moisture content and reduces the specific weight of dry soil. The results of single-axial experiments showed that nanoclay has a positive effect on increasing the unconfined compressive strength of soils versus reducing the corresponding strain, so that nanoclay increases the soil elastic modulus. Another part of the results of this research indicates the increase in adhesion along with the shear strength of the soil due to the addition of nanoclay. Figure 9 shows the effects of nanoclay on the soil. The results show the positive effect of nanoclay on the soil. By increasing the nanoclay, the soil compression strength reached $1.35 \mathrm{~kg} / \mathrm{cm} 2$ with a strain of 1.12 for the free-nanoclay soil and reached to $2.1 \mathrm{~kg} / \mathrm{cm} 2$ with a strain of 1.185 for the soil containing nanoclay.

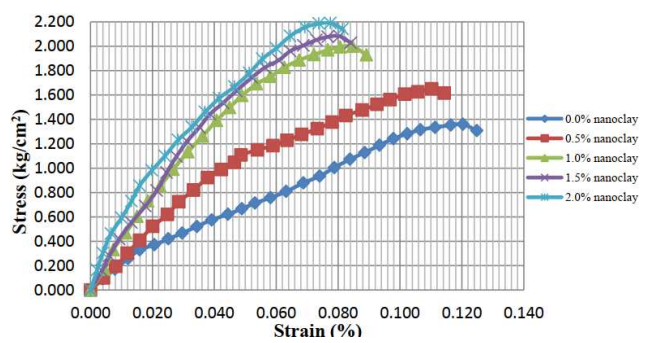

Figure 9. The effect of nanoclay on soil resistance

Majed and Taha (2012) examined the effect of nanomaterials on the geotechnical properties of Malaysia's organic peneng clay. The selected nanomaterials were nano magnesium oxide and nanoclay with 0.5 to 1 weight percent of soil. Adding each of the nanomaterials reduces the Atterberg limit and pasty Index and increases the maximum dry specific weight of the soil. In addition, soil resistance properties have improved so that by increasing the number of nanomaterials, the compression strength initially has a rising trend and then decreases. Figure 10 shows the effect of different nanomaterials on compression strength.

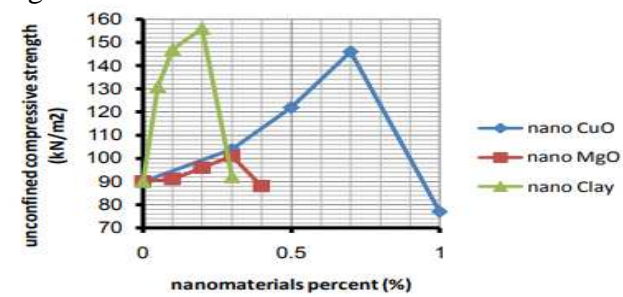

Figure 10. The effect of different nanomaterials on compression strength 
Ganji et al. (2012) investigated the effect of nanoclay on shear stress variations in a clay silicate soil. Comparing the results of single-axial compression tests in two conditions with the presence and absence of nanoclay shows, that shear stress of the soil will increase using the nanoclays.

Taipodia et al. (2011) investigated the effect of calcium dichloride, calcium oxide and potassium nitrate nanoparticles on clay properties. Their results indicated increase in shear strength, reduction in permeability and reduction in compressibility under the adding nanoparticles. Taha and Taha (2012) investigated the effect of adding different types of nanoparticles, including nano-aluminum, nano-copper, and nanoclay, on the swelling and contracting behavior of clay. Their results showed that the adding nanoclay had an impalpable effect on the optimum moisture content and maximum dry specific weight of the samples and by adding nanoclay, the pasty index, and soil contraction limit increases. Mohapatra and Anand (2010) acknowledged that the MohrCoulomb rupture is identified by two parameters: adhesion and internal friction angle. In general, intact soils, rich of nanoparticles, except for smectite and halloysite, have a higher friction angle and adhesion due to the bond between nanoparticles and other particles of soil that results in a relatively larger and stronger aggregate. For smectite due to the formation of thick dual electric layers on its surfaces, direct particle contact rarely happens; hence, its friction angle is the least in all clay types. However, halloysite may have significant effect on degradation of under pressure soil due to its low volumetric density and weak intralayers bond. On the other hand, there are groups of fibrous nanoparticles that can increase the shear strength of the soil through their tissue effect, just like arming with fiber. The effects due to intralayer tissue effect and the effect of surface adsorption may significantly increase the shear strength of the soil.

\section{DISCUSSION AND CONCLUSION}

In this paper, the use of nano additive materials in soil stability and resistance, with clay and its effects and results have been studied. In most nanosilica studies, nanoclay, nano-polymer, nano iron oxide, and kaolinite nanoparticles were used. Due to smaller dimensions, nanoparticles have a specific surface and are actively reactive with other particles in the soil matrix. Even one minute of these nanoparticles can have tremendous effects on soil engineering properties. This study showed that nanoparticles affect strength, permeability, compression, density, indices, and resistance. In this research, 19 studies on the effect of nanomaterials on soil resistance were investigated. Table 2 shows types of nanomaterials used in articles and figure 11 shows comparison of the nanomaterials used in the articles. According to figure 11, it is observed that the nanoclay is the most common nanomaterial used in papers to increase the strength of the soil. Thus, it can be concluded that nanoclay has a greater effect on the resistance of clay than other nanomaterials. It is recommended that this research be done for other soils.

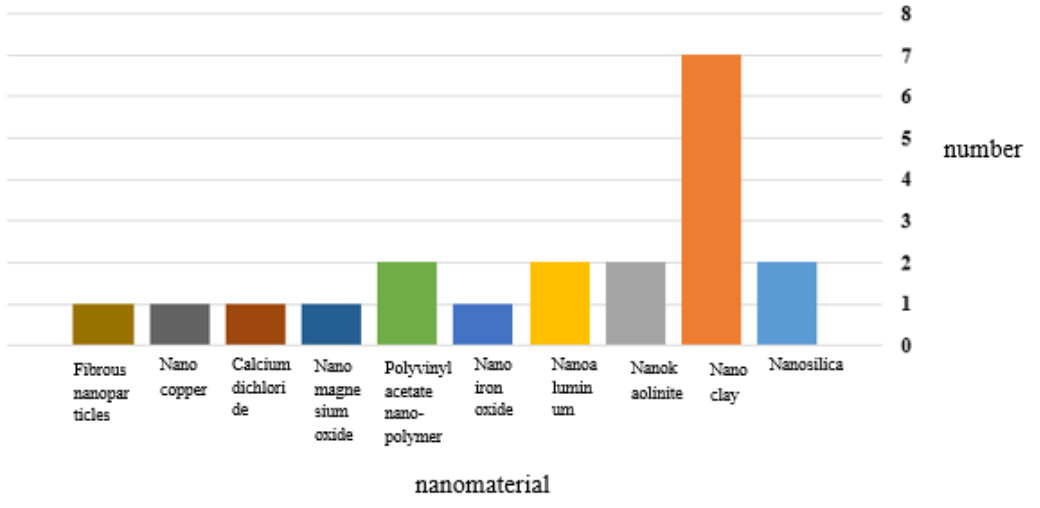

Figure 11. Comparison of used nanomaterials in article

Table 2. Types of nanomaterials used in articles and their effectiveness

\begin{tabular}{|c|c|c|}
\hline Effect of nanomaterial on soil & Authors & Nanomaterials \\
\hline $\begin{array}{l}\text { Improvement of soil mechanical and } \\
\text { resistance properties }\end{array}$ & $\begin{array}{l}\text { Changizi and Haddad (2018) and Botroun } \\
\text { et al. (2019) }\end{array}$ & Nanosilica \\
\hline $\begin{array}{l}\text { Reduction in soil dispersion and } \\
\text { improvement of resistance parameter }\end{array}$ & Abbasi et al. (2018) & Nanoclay \\
\hline $\begin{array}{l}\text { Increase in optimum moisture and } \\
\text { reduction in soil dry specific weight }\end{array}$ & $\begin{array}{l}\text { Bahari et al. (2012) } \\
\text { Ganji }\end{array}$ & \\
\hline $\begin{array}{l}\text { Increase in optimum moisture and } \\
\text { reduction in soil dry specific weight }\end{array}$ & Fakhri et al. (2012) & Nanokaolinite \\
\hline $\begin{array}{l}\text { Increase in adhesion, increase in shear } \\
\text { strength }\end{array}$ & Majdi et al. (2017) & \\
\hline $\begin{array}{l}\text { Increase in single-axial strength and } \\
\text { soil mechanical resistance }\end{array}$ & $\begin{array}{l}\text { Ghafarpour Jahromi and Zahedi (2018), } \\
\text { Taha and Taha (2012) }\end{array}$ & Nanoaluminum \\
\hline Increase in soil resistance parameters & Changizi and Haddad (2015) & Nano iron oxide \\
\hline Increase in compression resistance & Tadayonfar et al. (2014) & Polyvinyl acetate nano-polymer \\
\hline Increase in compression resistance & Tabatabaei and Salamat (2013) & \\
\hline Improvement of resistance properties & Majed and Taha (2012) & Nano magnesium oxide \\
\hline
\end{tabular}




\begin{tabular}{lll} 
Increase in shear resistance, reduction & Typodia et al. (2011) & Calcium dichloride, Calcium oxide and \\
in permeability and density & & Potassium nitrate nanoparticles \\
Increase in pasty index & Taha and Taha (2012) & Nano copper \\
Increase in shear resistance & Mahapatra and Anand (2010) & Fibrous nanoparticles \\
\hline
\end{tabular}

\section{References:}

Abbasi, N., Farjad, A., Sepehri, S., 2018. The use of nanoclay particles for stabilization of dispersive clayey soils. Geotechnical and Geological Engineering, 36(1), pp. 327-335.

Bahari Dalivand, M., 2012. Experimental study of silts geotechnical properties improvement by nanoclay, dissertation of Master of Science, Gilan University.

Butron,C., Axelsson, M., Gustafson, G., 2009. Silica sol for rock grouting: Laboratory testing of strength, fracture behavior and hydraulic conductivity, Tunnelling and Underground Space Technology, 24(6), pp. 603-607.

Changizi, F., Haddad, A., 2015. Strength properties of soft clay treated with mixture of nanoSiO2 and recycled polyester fiber, Journal of rock mechanics and Geotechnical Engineering, 7, pp. 367-378.

Changizi, F., Haddad, A., 2018. Improving the geotechnical properties of soft clay with nano-silica particles. Proceedings of the Institution of Civil Engineers-Ground Improvement, 170(2), pp. 62-71.

Fakhri, Z., Pourhosseini, R., Fakhri, M.H., 2012. Study the effect of nanoclay on basic geotechnical properties of kaolinite clay, collections of articles of the ninth international conference of civil engineering, Isfahan University of Technology, Isfahan, Iran, May 9-11.

Ganji, H., Fazl Avali, R., Norouznezhad, V., 2012. Investigation of soil shear stress variations before and after using nanoclays, collections of articles of the ninth international conference of civil engineering, Isfahan University of Technology, Isfahan, Iran, May 9-11.

Ghafarpour Jahromi, S., Zahedi, H., 2016, modifier evaluation of nano on volumetric and mechanical properties of fine-grain clay, Journal of Amirkabir civil engineering.

Hashemi Tabatabaei, S. 2013. Study of problematic soils in Iran and providing amending solutions, research plan of road, housing and urbanizing researches center.

Majdi, M., Oroumieie, A., Nikoodel, M. 2017. Improvement of geotechnical properties of clay soil by kaolinite nanoparticles.

Majed, Z.H., Taha, M.R., 2012. Effect of Nanomaterial Treatment on Geotechnical properties of a Penang Soil, Asian Scientifiv Research, 2(11), pp. 587-592.

Majeed Z. H., Taha M. R., Jawad I. T., 2014. Stabilization of soft soil using nanomaterils, Research Journal of Appiled Sience, Engineering and Technology, 8(4), pp. 503-509.
Mohammadi, M. and Niazian, M., 2013. Investigation of nanoclay effect on geotechnical properties of rasht clay. International Journal of Advanced Scientific and Technical Research, 3(3), pp. 37-4.

Mohapatra, M., and Anand, S., 2010. Synthesis and Applications of Nano-structured Iron Oxides/Hydroxides, International Journal of Engineering, Science and Technology, 2(8), pp. 127-146.

Neethu, S.V. Remya, S. 2013. Engineering behaviour of nanoclays stabilized soil. In: Proceedings of Indian Geotechnical Conference, 22-24 December, Roorkee University, $174 \mathrm{TH}-13$.

Tabatabaei, S., Salamat, A., 2013. Study of problematic soils in Iran and providing amending solutions, research plan of road, housing and urbanizing researches center.

Tadayonfar, Gh., Kazemi, R., Tadayonfar, V., 2014. Reinforcement of mechanical properties of silty soils by polyvinyl acetate polymer, the first national conference of soil mechanic and foundation engineering, Shahid Rajaee Teacher Training University, Tehran.

Taha M. R., Taha O. E., 2012. Influence of nano-material on the expansive and shrinkage soil behavior", Journal of Nanoparticle Research, 14(10), pp. 1-13.

Taipodia J., Dutta J., Dey A.K., 2011. Effect of nanoparticles on properties of soil, Proc, of Indian Geotechnical Conference, December, Kochi. 